\title{
Enacting The Spirit Of The United Nations Convention On The Rights Of Persons With Disabilities: The Role Of Postsecondary Faculty In Ensuring Access \\ Irene M. Duranczyk, University of Minnesota, USA \\ Karen A. Myers, Saint Louis University, USA \\ Ellyn K. Couillard, Paine College, USA \\ Sara Schoen, University of Minnesota, USA \\ Jeanne L. Higbee, University of Minnesota, USA
}

\begin{abstract}
Nations throughout the world have signed the United Nations (UN) Convention on the Rights of Persons With Disabilities. Many postsecondary educators support the ideals of access and equity for students with disabilities, but have received no training in how to ensure that these goals are achieved. This paper introduces the concepts of universal design and universal instructional design and provides specific guidelines for general communication and for creating accessible classrooms, lectures or presentations, documents, media, websites, and distance education courses.
\end{abstract}

Keywords: Access; Inclusion; Disabilities

\section{INTRODUCTION}

2rticle 24 of the United Nations (UN; 2006) Convention on the Rights of Persons With Disabilities addresses education; it reads, "States Parties recognize the right of persons with disabilities to education. With a view to realizing this right without discrimination and on the basis of equal opportunity, States Parties shall ensure an inclusive education system at all levels ...." Although Article 24 further states that "appropriate measures" will be taken "to train professionals and staff who work at all levels of education," in many nations professional development for all postsecondary faculty related to "disability awareness and the use of appropriate augmentative and alternative modes, means and formats of communication, educational techniques and materials to support persons with disabilities" is not as yet a reality. The purpose of this paper is to fill in some of the gaps in faculty knowledge about specific strategies they can use to ensure access and inclusion.

\section{Definitions}

According to Article 1 of the UN (2006) Convention, "Persons with disabilities include those who have long-term physical, mental, intellectual or sensory impairments which, in interaction with various barriers, may hinder their full and effective participation in society on an equal basis with others."

Article 2 of the UN (2006) Convention provides the following definitions provided here verbatim:

"Communication" includes languages, display of text, Braille, tactile communication, large print, accessible multimedia as well as written, audio, plain-language, human-reader and augmentative and alternative modes, means and formats of communication, including accessible information and communication technology. 
"Language" includes spoken and signed languages and other forms of non-spoken languages.

"Discrimination on the basis of disability" means any distinction, exclusion or restriction on the basis of disability which has the purpose or effect of impairing or nullifying the recognition, enjoyment or exercise, on an equal basis with others, of all human rights and fundamental freedoms in the political, economic, social, cultural, civil or any other field. It includes all forms of discrimination, including denial of reasonable accommodation.

"Reasonable accommodation" means necessary and appropriate modification and adjustments not imposing a disproportionate or undue burden, where needed in a particular case, to ensure to persons with disabilities the enjoyment or exercise on an equal basis with others of all human rights and fundamental freedoms.

"Universal design" means the design of products, environments, programmes and services to be usable by all people, to the greatest extent possible, without the need for adaptation or specialized design. "Universal design" shall not exclude assistive devices for particular groups of persons with disabilities where this is needed.

\section{Universal Design}

Universal design (UD) provides a critical framework for the enactment of the UN Convention. Conceived by Ron Mace at North Carolina State University (Center for Universal Design, 2010a, 2010b), UD encourages architects to consider all potential users of a space or environment when developing its design, thus eliminating the need to modify or add to the design later. What makes UD so inviting is that many of the design features that may be included to provide access for people with specific disabilities benefit everyone. For example, people with and without disabilities make use of curb cuts and automatic door openers.

The UN (2006) Convention promotes UD, articulating in Article 4 - General Obligations:

to undertake or promote research and development of universally designed goods, services, equipment and facilities, as defined in article 2 of the present Convention, which should require the minimum possible adaptation and the least cost to meet the specific needs of a person with disabilities, to promote their availability and use, and to promote universal design in the development of standards and guidelines.

However, the Convention also notes that, in some cases, individual accommodations for some people with disabilities are still necessary. It is impractical to hire sign language interpreters for every class rather than for those classes in which students who sign are enrolled. And some students who are deaf may prefer real-time captioning rather than signing, but in either case, the faculty member must speak slowly and clearly enough for an interpreter to be able to provide a complete record of what is being said. Similarly, recorded books may be necessary for some students who are blind, while others may prefer reading in Braille. Students with low vision, learning disabilities, or Attention Deficit Disorder (ADD) may benefit from using screen readers, as may some students who learn more efficiently when listening than when reading or when doing both simultaneously; but that does not mean that institutions must provide screen reading technologies for all students. What is does mean is that faculty must ensure that the documents they provide for all students can be read by a screen reader.

\section{Universal Instructional Design}

Universal instructional design (UID; Silver, Bourke, \& Strehorn, 1998) is one of several models that have been developed to apply UD principles to teaching and learning. Implementing UID requires the faculty member to consider all the potential students for a course and then choose or design course materials that will be accessible to everyone, understanding that, in some cases, assistive devices may be needed. There are a number of resources available to assist faculty in considering strategies for implementing UID in different contexts and academic disciplines (e.g., Bowe, 2000; Burgstahler \& Cory, 2008; Goff \& Higbee, 2008; Higbee \& Goff, 2008).

Without the implementation of UID, postsecondary students with disabilities must disclose the existence of the disability to the faculty member to receive accommodations. Disclosure can be a very difficult decision and process (Uncertain welcome, 2002). Students who receive accommodations are often segregated from others (e.g., 
to take exams with extended time) or experience disclosure of their disability to their classmates when accommodations are provided. When instruction is universally designed, some students with disabilities will not have to disclose because the accommodations they need are already built into the course. Examples include providing lecture notes on the course website, captioning all videos, and presenting information using multiple modalities that reflect students' varied learning styles. The following sections of this paper will address implementation of UD and UID as related to classrooms and other learning spaces, language and communication, lectures and presentations, documents, media, websites, and distance education courses.

\section{CLASSROOMS AND OTHER LEARNING SPACES}

Faculty members seldom get to choose the classrooms in which they teach, so it is important that, at the institutional level, administrators are aware that the following guidelines should be met:

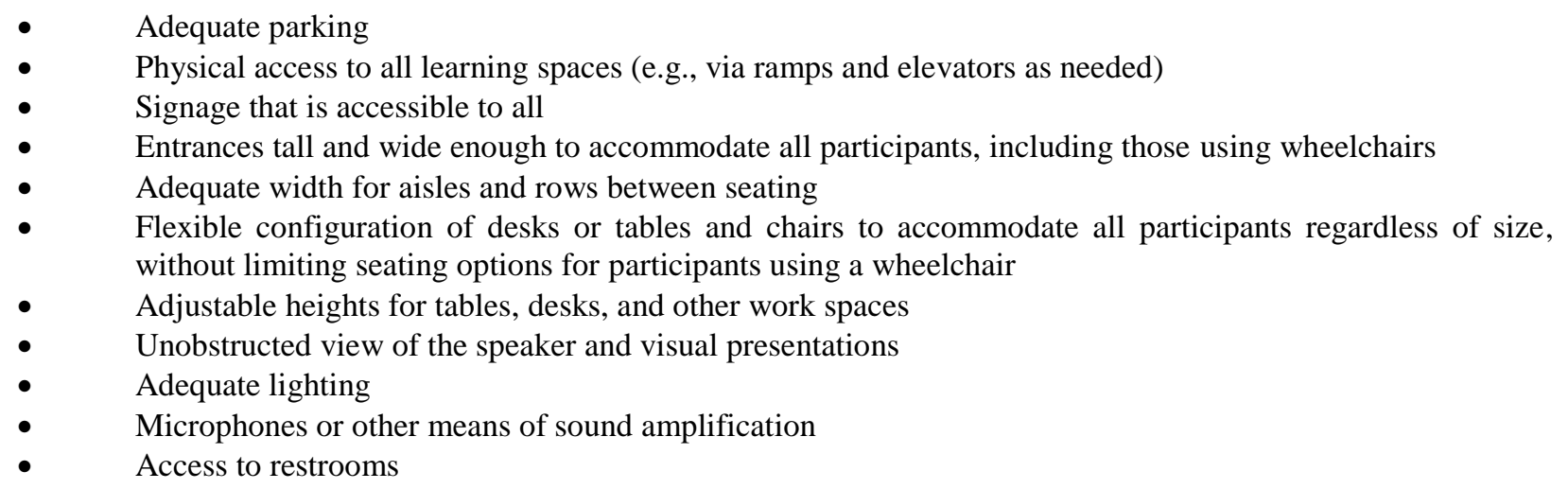

However, there are also steps that individual faculty members can take to make all students more comfortable, such as providing breaks in classes that meet for long periods of time. On the first day of class, the teacher can post a sign outside the classroom door to indicate the name of the course and the time it meets so that students will be certain they have found the correct room. There are also strategies that faculty can use to overcome structural problems in classrooms that are not universally designed. For example, rather than writing on a blackboard or whiteboard that may be difficult to see from a distance in a large lecture hall with poor lighting, faculty can use a projector when presenting formulas, diagramming sentences in international languages, or performing mathematics calculations in class. If seating arrangements are not flexible, faculty can have students work in small groups with others seated around them rather than expecting students to move or change seats to create groups. Whether or not a microphone is provided, faculty must speak slowly, clearly, and loudly enough for all to hear and understand. It is also important to repeat questions posed by students before responding to them so that all students in the classroom hear both the question and the answer. Additional ideas about communication are provided in the next section of this paper.

\section{LANGUAGE AND COMMUNICATION}

As previously noted, the UN (2006) Convention defines communication very broadly. Documents, presentations, and media will be addressed in later sections of this paper, but it is also important to consider aspects of interpersonal communication and the power of language (Clinton \& Higbee, 2011). The American Psychological Association (2010) has suggested that writers "put the person first" (p. 72), a strategy that is modeled in the UN Convention. By placing the person first (e.g., the student who is deaf, the young man using a wheelchair, the woman who has dyslexia), the speaker or writer is indicating that the disability does not define the person; it is but one of many aspects of the individual's identity. Meanwhile, it is imperative to eliminate language that dehumanizes, ridicules, or invokes pity (e.g., confined to a wheelchair, suffering from epilepsy). In the U.S., words associated with disability are freely used in popular culture to refer to being clumsy ("What a spaz!") or stupid ("That's so lame!" "How retarded can you get?!"). When expressions like these are used in educational settings, they should be considered teachable moments to educate students and colleagues about disability, and continued use should not be tolerated (Tregoning, 2009). 
Myers, Lindburg, and Neid (in press) have provided helpful guidelines for communicating with people with disabilities. Regardless of the nature of the disability, one should not ask intrusive questions of a personal nature or make stereotypic assumptions. It is not appropriate to do something for the individual unless asked to do so or having inquired about performing the task. Being respectful requires speaking directly to the individual, not to the interpreter, companion, or care giver. When encountering a person with a visual disability, it is important to introduce oneself before beginning a conversation. When speaking to someone who is deaf or hard of hearing, it is helpful to be expressive, but not to speak louder or decrease the rate of speech unless asked to "speak up" or "slow down." Keeping in mind the many visual cues that a person who is deaf may use to interpret speech, it is critical not to cover one's mouth when speaking. These are but a few of the suggestions provided by Myers et al.

\section{LECTURES AND PRESENTATIONS}

One of the primary ways that faculty impart knowledge to students is via course lectures. When determining how to prepare presentations, it is imperative to consider accessibility issues. Platforms like Prezi can be visually stimulating, but Prezi does not support assistive technology. It is suggested that Prezi presentations be developed first in PowerPoint, which is accessible if created with accessibility in mind, and then supplement the accessible presentation with a Prezi link. The key is maintaining the same content and level of engagement.

\section{PowerPoint}

Guidelines for PowerPoint presentations include using a sans-serif font such as Arial, Arial Black, Tahoma, or Calibri. Minimum font size for readability both when projected and in handout form is 28-point, but 32-point is preferred. If not using black text on a white background, choices of colors for text and background should provide a stark contrast (e.g., white text on dark blue background). It is critical to use the slide layout options available in PowerPoint rather than creating titles by using the enter key or columns by using the tab key. Every slide should have a title, and titles should not be repeated. The titles are one of the primary mechanisms that assist a person using a screen reader in accessing slide content in the correct order and making sense of the slideshow as a whole.

Artwork, photos, and other graphics should not be included within the presentation unless they contribute to its content. If visuals are used, descriptions must also be provided. Depending on how the PowerPoint will be accessed by students (e.g., as a class presentation or on a course website), descriptions of any content that cannot be accessed by screen reader can be provided on a previous slide or using the Comments function in PowerPoint. Descriptions of photos and other artwork should be as rich and accurate as possible while not adding interpretation. In other words, they should describe the visual as a student in the class seeing the visual for the first time might describe it to a classmate. When presenting in class, the speaker should read the description aloud so that students who cannot see it still know what it is. The Web Accessibility in Mind (WebAIM, 2013a, 2013b) initiative at Utah State University is an excellent resource for information on PowerPoint accessibility.

\section{Handouts}

Whether or not to provide handouts of presentations also has accessibility implications. For the sake of the environment, many faculty provide their presentations in advance on their course websites and then students can choose whether to print copies to bring to class or to access the file electronically while sitting in class. In a perfect, universally-designed world, faculty would provide online access in advance of class and large print paper copies (i.e., one slide per sheet of paper) for all students during class, so that no student would be singled out to receive large print, but it is understood that this is not a good use of our natural resources. However, if paper copies are being provided, they should be provided for all students, with large print versions available to those who need them. Again, if printing six slides per side of paper, adhering to the minimum 28-point font will enable students without disabilities to read the slides without difficulty.

Some faculty members are not willing to provide their presentations electronically or in paper formats because they consider this work their intellectual property, not to be shared with others who have not paid tuition to attend their classes. Other faculty fear that if they provide their presentations on their course websites, students will not attend class. One faculty member (Arendale \& Ghere, 2008) addressed this concern by providing an alternative 
version of his PowerPoint presentation that only included the headings and major subheadings, and filling in the supporting details in class.

\section{Videos}

Any videos used in class must be captioned, including videos created by the faculty member. Some institutions provide resources for captioning if it is known that a student with a hearing impairment will be enrolled in the course. However, faculty do not necessarily know well enough in advance if there will be a deaf student in the class, so they should always be prepared.

The captioning feature should always be turned on to benefit all students in the class. For students who are not native speakers of the language in which the course is being taught, captions can be very helpful. Other students may retain written information more effectively than that conveyed orally or through visual stimuli other than the printed word. Meanwhile, for all students using as many of their five senses as possible in the learning process can be helpful.

Just as captioning makes videos accessible to students who are deaf, descriptive video services provided by Descriptive Video Works (n.d.) and similar organizations provide audio descriptions of the action in a film for people who are blind. The descriptions are carefully developed to avoid adding bias or any information that would not be apparent to anyone else "watching" the video. Showing a video that has been created using descriptive video services enables all students to understand how they could be more descriptive in their writing and is a helpful teaching tool.

\section{DOCUMENTS}

When creating documents using a word processor, accessibility issues can be minimized by using the structural components of most word processing software. There are two important levels or views to accessible documents - the physical and the tagged view. The physical view is that which is seen when a document is printed. The tagged view is what assistive technology sees and how assistive technology organizes the view for electronic readers. It structures the content for assistive technology just as type size, indentation, and color may assist a person with sight to garner clues into the organization and importance of document contents. The structural components of word processing applications add tags to documents that guide assistive technology and make the structure of the documents visible to electronic readers.

The most accessible documents are created with HTML tags (WebAIM, 2013). Most word processing documents, when converted properly to a Portable Document File (PDF) file, will retain their accessibility features and will be more accessible than the word processing HTML document tags that are embedded in the software application. PDF files can be opened directly in the web browser and be accessible. Although alternative text (ALT) can be recorded and transferred in Microsoft Word documents, they are not always easily accessible to screen readers when opened in a web browser unless they are converted to a PDF. Microsoft Word documents retain their maximum accessibility only when they are opened in Microsoft Word (WebAim, 2013). This is quite common with many software applications.

The primary structural components that are required for accessibility are (a) heading and subheading tags; (b) alternative text for tables, charts, pictures, and media; (c) readable Universal Resource Locators (URLS) with complete descriptions visible in the print document and embedded in electronic documents; (d) structured numbering and bulleted lists using the formatting tools within the word-processing application; and (e) structured tables with true row and column headings, rather than tables created through the use of the tab key. All of these features are available in most word processors and are transferred when properly converting to a PDF document.

In addition to these structural tags embedded within documents, it is important to use sans serif fonts for readability. Although page navigation can be supplemented by using color, size of type, and indentations for someone who has sight, these techniques cannot be the prime mechanism for leading the reader through the document. Headings, subheadings, lists, and other structural styles features of the word processor must be the 
primary source of guidance for document organization. When multiple tabs, spaces, and paragraph entries have been used to make a document look pleasing, an assistive technology device will record and relay the message to the reader. For example, a screen reader will interpret and speak five spaces for a paragraph indent as "space, space, space, space, space" prior to speaking the first word of the sentence beginning the paragraph, and likewise for multiple paragraphs or tabs in a row. One can imagine how annoying this could get with multiple spaces, tabs, and line returns in the middle of the content students are trying to learn. Using "styles" and table and paragraph settings in Microsoft Word will eliminate this confusion. Information on web-based resources and assistive technology advancement for various word processors and office suites are available online (e.g., WebAIM, 2013a, 2013c). Keeping abreast of universally-designed software saves time and supports all students' ability to navigate documents.

A final consideration is the transferability of documents. Can the document be transferred to another operating system? Is it accessible by mobile or stationary platforms? Can the document be visible and rendered with all its accessibility in various browsers? Is the document accessible for transferability by assistive technology? These are the questions that need to be answered before purchasing or investing time and money in products that may not meet Americans with Disabilities Act (ADA; 1990) or UN (2006) Convention standards. Both the World Wide Web Consortium (W3C, 2012, n.d.) and WebAIM keep updated information on accessible software.

\section{MEDIA}

In a world enhanced by multimedia and access to visual and audio resources on mobile devices as well as televisions or stationary computers, instruction can be delivered or supplemented by many media resources. Whether one is a visual, aural, or kinesthetic learner or prefers an active or passive learning environment, media have a role in the delivery of information. As advancements have occurred in print and online documents, so too have advancements in the accessibility of media resources. The primary functions of media (i.e., to inform, instruct, demonstrate, reinforce concepts) should be accessible regardless of the audience. Consideration must be given to potential audience members who are blind or have limited vision or color perception, people who are deaf or have a limited range of hearing or hearing sensitivities, people with mobility impairments or limited dexterity, people with photosensitive epilepsy, and so on. In order to make media accessible, audio materials should be accompanied by transcripts or captioning, and visual materials should be accompanied by detailed audio materials not only relaying the dialogue but also narrating the setting and action so that one can contextualize the information with the necessary descriptive visual clues. Materials that are delivered with the need for kinesthetic engagement must be supported by keyboard movements and directions rather than mouse-only or vision-based controls.

There are a host of resources to support balanced media. YouTube is a visual and audio resource that is supported by captioning, ancillary scripts, and keyboard movements to navigate. As with document tags for navigation (e.g., heading structure, alternative text for visual materials), media materials use the same structural tags for accessibility. All media resources on a website or course management system must have supports for easy access. On occasion one can choose a product that is not supported by audio, visual, and kinesthetic supports only if it is accompanied by an alternative tool that does support all learners and contains the exact content and level of engagement. $\mathrm{W} 3 \mathrm{C}$ and WebAIM maintain updated guidelines on media accessibility for mobile or stationary platforms.

Transferability of media to alternative platforms, operating systems, media readers, and adaptive technology must also be considered. Because of the variety of mobile and stationary systems students use to access information, media platforms must consider the range of users and their preferences. For example, iPads and other tablets may not support the same software or platforms students use on their computers. Faculty need to be aware of how students are accessing web-based materials and then design instructional materials to be accessible by all, or make it clear if there are limitations to how materials can be accessed.

Social media, too, need to address accessibility issues. Twitter, Facebook, LinkedIn, and some aspects of YouTube lack the structural tags to make navigation on the site universal with assistive technology. When using inaccessible social media to share audio or visual materials, it is necessary to provide video description and audio transcription. It is best to read the accessibility reports on all media before designing or adopting media tools for instructional purposes. 


\section{WEBSITES}

With the growth of the World Wide Web, the Web Accessibility Initiative (WAI) was launched in 1997 by W3C (n.d.). This resource is the most up-to-date and comprehensive resource for addressing web content, web browsers, media players, authoring tools, and evaluation tools. A second web-based resource with extensive documents accessible to nontechnology personal is the WebAim (2013) site. WebAIM also provides resources to inspect, report issues, and certify websites. The general guidelines are similar to the structural guidelines for documents and audio resources (Miller, Rowland, \& Virgin, 2002). This is an ever-changing field; authoring tools and the ability to add media within websites keep changing. Using the online tools at WebAim or a similar publiclyfunded worldwide resource for evaluating tools and final designs of websites is imperative. The principles are the same as those previously discussed - a simple, yet informative, structure supported by tags; attention to the various supports for persons with aural, visual, or kinesthetic challenges; and checks for the ordering of information, guided by tags within the page's hidden documents. There are simulations at WebAIM for experiencing navigation of websites for people with low vision, dyslexia, distractibility or using a screen reader. Experiencing the difficulties embedded in a webpage that is not optimally designed for access for all can help faculty without aural, visual, or kinesthetic challenges understand why design must be considered when creating webpages.

Transformability continues to be an issue to watch. The variety of browsers, operating systems, platforms, and devices for accessing webpages add to the challenge. The rapid changes in technology also increase the need for reliance on a technology team that is familiar and committed to the UN (2006) Convention or ADA (1990) compliance.

\section{DISTANCE EDUCATION}

A beauty and challenge of distance education is open access to all without requiring all students to attend a particular classroom or campus. On one hand, everyone has access, and on the other hand, faculty and staff may be less aware of the challenges that individual students face as they navigate the online course site.

\section{Sense of Community}

One of the most important initial steps in designing an accessible online course is to create a sense of community among participants. Faculty members should introduce themselves using several mechanisms (e.g., written document, video, PowerPoint) that accommodate different preferred learning styles and ways of knowing. Students should also have the opportunity to introduce themselves using the mechanism of their choice, but it is imperative that these introductions be accessible to all students participating in the course. In addition, students can be involved in developing the "netiquette" guidelines for the course.

\section{Course Site Design}

One challenge of designing course sites is the fact that most institutions have particular platforms that they support and faculty and staff are required to work within those systems. Working with disability compliance officers on campus will be most important. Understanding the structural design of the platform is another issue. The underlying structural tags of the site with its organizational tags must be understood by the technology team and the instructor working on the site. For example, if required titles are set at a level-three heading, instructors adding an additional level of subheading must create a level-four heading in the style sheet. If side bars of a course site are the last areas the screen reader will read, then important information, such as introducing the instructor, must be in the main area of the site rather than the sidebars. Working with the technology team to understand the hidden structure of a course site will be very important.

Within the site, consistency of language and very detailed and clear directions are needed to support the course design so that students know what, when, and how to access information and submit assignments. As faculty members design their sites and each document, presentation, and video they intend to post to the site, they must constantly keep in mind that they will not be available 24 hours per day to respond to questions that arise in asynchronous course delivery in the same way that they would be present to respond to students' questions and concerns when a class meets face-to-face; anticipating possible problems is important. 


\section{CONCLUSION}

This paper barely scratches the surface of the complexity of educational access for persons with disabilities by addressing the structural concerns that can guide an inquiry into accessibility for all. As technology advances and reliance on technology increases, there must be vigilance on the parts of faculty, instructional technology support personnel, and students to ensure that everyone is included; everyone has a role in increasing access for all. Steps that faculty can take include asking questions, regularly checking accessibility websites such as WebAIM and W3C for updated information, and reporting concerns to software designers when technology falls short. The structures for human rights have never been stronger, but it is the vigilance of the people using technology that will ensure that we continue down the path of access, equity, and success for everyone.

The UN (2006) Convention on the Rights of Persons With Disabilities has laid a critical foundation for accessible education throughout the world. It has established definitions that can be understood across cultures and has increased awareness and implementation of universal design. However, it will require the efforts of all educators, as well as policy makers, communities, families, and peers to eliminate the achievement gap among and within nations and make equity in education a reality. The challenges for postsecondary education are considerable, and given the proportion of persons with disabilities who do not complete secondary education, it is imperative that those who are qualified have the opportunity for access to - and success in - higher education. Good intentions on the part of administrators, faculty, and staff are not enough. Institutions should provide the professional development needed to support all faculty in developing the skills to create fully accessible learning environments. Meanwhile, faculty members must take responsibility for availing themselves of training opportunities or seeking out the information needed if such opportunities are not provided. The resources cited in this paper can assist faculty members in serving as change agents to enact the spirit of the UN Convention.

\section{AUTHOR INFORMATION}

Irene M. Duranczyk is an Associate Professor in the Department of Postsecondary Teaching and Learning, with an EdD from Grambling State University, Louisiana. Irene has been involved in the research, design, implementation, and evaluation of Universal Instructional Design materials for mathematics and science courses and programs since 2002. She has conducted professional development workshops on UID for faculty and staff at private and public, 2 and 4 year institutions. She has been active in pre-college and postsecondary programs preparing non-traditional students for college level mathematics since 1985. E-mail: duran026@umn.edu

Karen A. Myers, PhD, is Associate Professor and Director of Higher Education Administration at Saint Louis University and Director of the award-winning international disability education project, Allies for Inclusion: The Ability Exhibit. She has been a college teacher and administrator since 1979, recipient of the ACPA College Student Educators International Voice of Inclusion Medallion, Annuit Coeptis Senior Professional Award, and ACPA Diamond Honoree, co-founder of the ACPA Standing Committee on Disability, and current ACPA Foundation Board of Trustee. E-mail: kmyers11@ @lu.edu

Ellyn Couillard earned her Bachelor's degree at The University of Georgia in sociology with a minor in history. She also has a Master's degree from St. Cloud State University in College Counseling and Student Development. Ellyn has previously held positions with TRIO programs, advising, orientation and tutoring services. Currently, she serves as the Director of Academic Support at Paine College in Augusta, Georgia. She has passion for educating others about Universal Design and Universal Instructional Design and has presented on the subjects at numerous conferences. E-mail: ecouillard@paine.edu

Sara Schoen is completing an M.A. in Multicultural College Teaching and Learning at the University of Minnesota, Twin Cities, and then intends to pursue further credentialing through the University's Department of Curriculum and Instruction's Learning Technologies program, with a focus on Online Distance Learning. As a former urban high school math and social studies teacher, her interests include programs that empower nontraditional students to successfully transition to college and graduation. Her current work experience includes working for the University's Office of Human Resources Department within Organizational Effectiveness. Utilizing her daily work has piqued her interest in making online learning accessible, interactive, and relevant to learners. This includes exploring online identities in connection to student development. E-mail: $\underline{\text { scho0410@umn.edu }}$ 
Jeanne L. Higbee has worked in higher education since 1974. Currently she serves as Professor and Director of Graduate Studies in the Department of Postsecondary Teaching and Learning at the University of Minnesota, Twin Cities. She is a 2007 American College Personnel Association (ACPA) Diamond Honoree and the recipient of the ACPA Voice of Inclusion Medallion (2005) and Disability Ally Award (2008). In 2011 she received the University of Minnesota's Horace T. Morse-University of Minnesota Alumni Association Award for Outstanding Contributions to Undergraduate Education. In 2013 she received the University's Access Achievement Award. E-mail: higbe002@umn.edu (Corresponding author)

\section{REFERENCES}

1. American Psychological Association. Publication manual of the American Psychological Association (6 ${ }^{\text {th }}$ ed.). Washington, DC: Author.

2. Americans with Disabilities Act of 1990, 42 U.S.C.A. $§ 12101$ et seq. Retrieved from http://www.ada.gov/pubs/ada.htm

3. Arendale, D., \& Ghere, D. (2008). Teaching college history using universal instructional design. In J. L. Higbee \& E. Goff (Eds.), Pedagogy and student services for institutional transformation: Implementing universal design in higher education (pp. 113-130). Minneapolis, MN: University of Minnesota, Center for Research on Developmental Education and Urban Literacy. Retrieved from http://www.cehd.umn.edu/passit/docs/PASS-IT-Book.pdf

4. Bowe, F. G. (2000). Universal design in education-Teaching nontraditional students. Westport, CT: Bergin \& Garvey.

5. Burgstahler, S., \& Cory, R. (Eds). (2008). Universal design of postsecondary education: From principles to practice. Cambridge, MA: Harvard Education Press.

6. Center for Universal Design. (2010a). History of universal design. Raleigh, NC: North Carolina State University, Center for Universal Design. Retrieved from http://www.ncsu.edu/project/designprojects/udi/center-for-universal-design/history-of-universal-design/

7. Center for Universal Design. (2010b). Ronald L. Mace. Raleigh, NC: North Carolina State University, Center for Universal Design. Retrieved from http://www.ncsu.edu/project/design-projects/udi/center-foruniversal-design/ron-mace/

8. Clinton, L. C., \& Higbee, J. L. (2011). The invisible hand: The power of language in creating welcoming postsecondary learning experiences. Journal of College Teaching \& Learning, 8(5), 11-16. Retrieved from http://journals.cluteonline.com/index.php/TLC/article/view/4253

9. $\quad$ Descriptive Video Works. (2013). Descriptive video services. Retrieved from http://www.descriptivevideoworks.com/descriptive-video-services.cfm

10. Goff, E., \& Higbee, J. L. (Eds.). (2008). Pedagogy and student services for institutional transformation: Implementation guidebook for faculty and instructional staff. Minneapolis, MN: University of Minnesota, College of Education and Human Development. Retrieved from http://www.cehd.umn.edu/passit/docs/guidebook-2.pdf

11. Higbee, J. L., \& Goff, E. (Eds.). (2008). Pedagogy and student services for institutional transformation: Implementing universal design in higher education. Minneapolis, MN: University of Minnesota, Center for Research on Developmental Education and Urban Literacy. Retrieved from http://www.cehd.umn.edu/passit/docs/PASS-IT-Book.pdf

12. Miller, L., Rowland, C., \& Virgin, J. (2002). Keeping web accessibility in mind [video]. Logan, UT: Utah State University, Department of Special Education and Rehabilitation, ASD Project. Retrieved from http://webaim.org/intro/\#video

13. Myers, K. A., Lindburg, J. J., \& Neid, D. (in press). Allies for inclusion: Disability and equity in higher education. Washington, DC: Association for the Study of Higher Education.

14. Silver, P., Bourke, A., \& Strehorn, K.C. (1998). Universal instructional design in higher education: An approach for inclusion, Equity \& Excellence in Education, 31(2), 47-51.

15. Tregoning, M. E. (2009). Being an ally in language use. In J. L. Higbee \& A. A. Mitchell (Eds.), Making good on the promise: Student affairs professionals with disabilities (pp. 173-176). Washington, DC: American College Personnel Association and University Press of America. 
16. Uncertain welcome: Student perspectives on disability and postsecondary education [video]. (2002).

Minneapolis, MN: University of Minnesota, General College, Curriculum Transformation and Disability.

Retrieved from http://mediamill.cla.umn.edu/mediamill/display/70826

17. United Nations. (2006). Convention on the Rights of Persons With Disabilities. New York, NY: Author. Retrieved from http://www.un.org/disabilities/convention/conventionfull.shtml

18. WebAIM. (2013a). Designing for screen reader compatibility. Logan, UT: Utah State University, Center for Persons With Disabilities. Retrieved from http://webaim.org/techniques/screenreader/

19. WebAIM. (2013b). Introduction to web accessibility. Logan, UT: Utah State University, Center for Persons With Disabilities. Retrieved from http://webaim.org/intro/\#video

20. WebAIM. (2013c). Microsoft Word. Logan, UT: Utah State University, Center for Persons With Disabilities. Retrieved from http://webaim.org/techniques/word/

21. WebAIM. (2013d). PowerPoint accessibility. Logan, UT: Utah State University, Center for Persons With Disabilities. Retrieved from http://webaim.org/techniques/powerpoint/

22. World Wide Web Consortium. (2012). Standards. Retrieved from http://www.w3.org/standards/

23. World Wide Web Consortium. (n.d.). Web Accessibility Initiative. Retrieved from http://www.w3.org/WAI/ 